\title{
Measurement of Black Carbon and Particle Number Emission Factors from Individual Heavy-Duty Trucks
}

\author{
George A. Ban-Weiss ${ }^{\mathrm{a}}$, Melissa M. Lunden ${ }^{\mathrm{b}}$, Thomas W. Kirchstetter ${ }^{\mathrm{b}}$, Robert A. \\ Harley $^{\mathrm{c}, 1}$ \\ ${ }^{a}$ University of California, Dept. of Mechanical Engineering, Berkeley, CA 94720-1740 \\ ${ }^{b}$ Lawrence Berkeley National Laboratory, Atmospheric Science Dept., Berkeley, CA 94720 \\ ${ }^{c}$ University of California, Dept. of Civil \& Environmental Engineering, Berkeley, CA 94720-1710
}

\begin{abstract}
Emission factors for black carbon (BC) and particle number (PN) were measured from 226 individual heavy-duty (HD) diesel-fueled trucks driving through a $1 \mathrm{~km}$-long California highway tunnel in August 2006. Emission factors were based on concurrent increases in $\mathrm{BC}, \mathrm{PN}$, and $\mathrm{CO}_{2}$ concentrations (measured at $1 \mathrm{~Hz}$ ) that corresponded to the passage of individual HD trucks. The distributions of $\mathrm{BC}$ and $\mathrm{PN}$ emission factors from individual HD trucks are skewed, meaning that a large fraction of pollution comes from a small fraction of the in-use vehicle fleet. The highest-emitting $10 \%$ of trucks were responsible for $\sim 40 \%$ of total $\mathrm{BC}$ and $\mathrm{PN}$ emissions from all $\mathrm{HD}$ trucks. BC emissions were log-normally distributed with a mean emission factor of $1.7 \mathrm{~g} \mathrm{~kg}^{-1}$ and maximum values of $\sim 10 \mathrm{~g} \mathrm{~kg}^{-1}$. Corresponding values for PN emission factors were $4.7 \times 10^{15}$ and $4 \times 10^{16} \mathrm{H} \mathrm{kg}^{-1}$. There was minimal overlap among high-emitters of these two pollutants: only 1 of the 226 HD trucks measured was found to be among the highest $10 \%$ for both $\mathrm{BC}$ and PN. Monte Carlo resampling of the distribution of BC emission factors observed in this study revealed that uncertainties $(1 \sigma)$ in extrapolating from a random sample of $n$
\end{abstract}

\footnotetext{
${ }^{1}$ Corresponding author e-mail: harley@ce.berkeley.edu; phone: +1510 643 9168; fax: +1510 6427483
} 
HD trucks to a population mean emission factor ranged from $\pm 43 \%$ for $n=10$ to $\pm 8 \%$ for $n=300$, illustrating the importance of sufficiently large vehicle sample sizes in emissions studies. Studies with low sample sizes are also more easily biased due to misrepresentation of high-emitters. As vehicles become cleaner on average in future years, skewness of the emissions distributions will increase, and thus sample sizes needed to extrapolate reliably from a subset of vehicles to the entire in-use vehicle fleet are expected to become more of a challenge.

\section{Introduction}

Motor vehicle emissions of fine particles $\left(\mathrm{PM}_{2.5}\right)$ can adversely affect human health (1, 2), impair visibility, and alter the earth's radiative energy balance leading to climate change (3). Gasoline and diesel engines are significant sources of primary fine particle emissions, especially in urban areas (4). When normalized to fuel consumption, $\mathrm{PM}_{2.5}$ mass emission factors are more than an order of magnitude higher for heavy-duty (HD) diesel trucks compared to light-duty (LD) passenger vehicles (almost all gasoline-fueled) (5).

Black carbon (BC), which accounts for more than half of $\mathrm{PM}_{2.5}$ mass from diesel engines under load (5), is of particular concern. A recent assessment indicates that $\mathrm{BC}$ is the second largest contributor to global warming (next to $\mathrm{CO}_{2}$ ) and alters regional precipitation and snow and cloud albedos (6). Studies have suggested that reducing BC emissions, of which diesel engines are a major source, should be an element in the effort to counteract global warming (e.g. 7). Bond and Sun (8) note, however, that BC reduction 
in developed countries is relatively costly as a means for mitigating climate change unless local air quality and public health benefits are considered simultaneously.

Motor vehicles emit the largest number of particles in the ultrafine mode, defined as particles with diameter $\mathrm{D}_{\mathrm{P}}<100 \mathrm{~nm}(9,10)$. These particles are small enough to penetrate deeply into the lung, enter the circulatory system, and accumulate in organs such as the brain, heart, and liver (2). There is an ongoing debate about whether particle number (PN), mass, or chemical composition is most important in causing adverse human health effects (2). Current mass-based emission standards may not be optimal in reducing health effects if particle number turns out to be the more harmful factor.

One of the challenges in characterizing vehicle emissions is extrapolating from a sample of vehicles to the entire in-use population. HD trucks are especially time-consuming and expensive to test in the laboratory, and therefore dynamometer studies of HD vehicle emissions have generally been limited to small sample sizes (1-25 vehicles). On-road remote sensing techniques have been used to measure snapshots of gaseous pollutant emissions from large numbers of vehicles; remote sensing of PM emissions is difficult due to the need to relate integrated measures of particle optical properties back to particle number as a function of size and chemical composition. While measurements of vehicle emissions in roadway tunnels can capture a large sample of on-road vehicles, such studies usually provide only fleet-average results. 
It is known that high-emitting vehicles contribute disproportionately to gaseous pollutant emissions from the on-road LD vehicle fleet. Emission factor data from Bishop and Stedman (11) for $\mathrm{NO}_{\mathrm{x}}, \mathrm{CO}$, and hydrocarbons show that the skewness of emissions distributions (i.e., the relative importance of high-emitters as a source of vehicle-related pollution) has been increasing at the same time that fleet-average emissions have declined significantly. Gas-phase emissions from HD diesel vehicles have been found to be skewed to a lesser extent than light-duty vehicles (12). Less is known about PM emissions from motor vehicles, due in part to difficulties in making fast time-response measurements. Various studies have reported distributions of PM emissions for LD vehicles (13-15). Other studies have focused on PM emissions from large samples of high-emitting LD vehicles (16-18). Jiang et al. (19) reported distributions of BC and $\mathrm{PM}_{2.5}$ emissions for a mixed LD/HD fleet in Mexico City. Two other studies measured particle number emission rates, one from high-emitting HD diesel buses (20), and the other from trucks and buses in Mexico (21). In summary, to date there have been relatively few studies that report fine particle emission distributions from large samples of HD vehicles.

The goal of the present study was to measure $\mathrm{BC}$ and $\mathrm{PN}$ emission factors for a large sample of individual HD trucks as they drove through a San Francisco Bay area highway tunnel. The individual and joint distributions of $\mathrm{BC}$ and $\mathrm{PN}$ emission factors from these trucks are presented. We also consider how vehicle sample size affects uncertainty in estimates of the population mean $\mathrm{BC}$ emission factor. In a companion paper (5), we 
report fleet-average emission factors for gas- and particle-phase pollutants, separately for LD (nearly all gasoline) vehicles and HD diesel trucks.

\section{Experimental Methods}

\subsection{Field Measurements}

Vehicle emissions were measured at the Caldecott tunnel, located on highway 24 in the San Francisco Bay area. The tunnel has 3 traffic bores with 2 lanes each. In this study, HD truck emissions were measured in the southernmost lanes (bore 1) of the tunnel, where a mixture of LD vehicles and MD/HD trucks travel uphill on a 4\% grade. Truck emissions were measured on 4 days (19-21 and 24 July 2006) from 12-2 PM, which is the time of day when trucks comprise the largest fraction of total traffic in bore 1 of the tunnel.

Pollutant concentrations were measured near the exit (east end) of the tunnel with 1second time resolution. The sample inlets for the analyzers were located approximately $15 \mathrm{~cm}$ below the ceiling of the traffic bore, which was near the exhaust stacks of passing $\mathrm{HD}$ trucks. To measure $\mathrm{BC}$ and particle number concentrations, sample air was drawn through approximately $1 \mathrm{~m}$ of conductive silicone tubing to analyzers located above the traffic in a ventilation duct. A sharp cut cyclone (BGI, Waltham, MA, model VSCCA) was used to achieve a particle size cut of $2.5 \mu \mathrm{m}$. BC was measured using a singlewavelength aethalometer (Magee Scientific, Berkeley, CA, model AE-16) capable of high-time resolution measurements due to improved optoelectronics relative to older models. Particle number was measured using an ultrafine water-based condensation 
particle counter or CPC (TSI, Shoreview, MN, model 3786), which measures particles with diameter $D_{P} \geq 3 \mathrm{~nm}$. Due to high particle number concentrations inside the tunnel, CPC measurements were diluted by splitting the incoming aerosol flow. One line passed through an orifice and the other through a HEPA filter; the lines were recombined before passing into the CPC. The pressure drop across the orifice caused a large and stable fraction of the sample flow to pass through the HEPA filter that removed all of the particles, leading to a dilution ratio of 15.2. A parallel $\sim 40 \mathrm{~m}$ Teflon sample line carried tunnel air to a non-dispersive infrared $\mathrm{CO}_{2}$ analyzer (LI-COR, Lincoln, NE, model 820), located in the east end tunnel fan room. In order to align the plumes, BC and PN data were shifted by 25 seconds to account for the longer residence time in the $\mathrm{CO}_{2}$ analyzer inlet line.

Laboratory experiments (22) showed that BC concentrations reported by aethalometers erroneously diminish as the collecting filter becomes increasingly loaded with strongly light-absorbing particles within each operating cycle between filter tape advances. Therefore, in our study, raw data from the aethalometer were adjusted as recommended by Kirchstetter and Novakov (22) using eq. 1,

$$
B C=\frac{B C_{0}}{(0.88 T r+0.12)}
$$

where $\mathrm{BC}_{0}$ and $\mathrm{BC}$ are the raw and adjusted concentrations respectively $\left(\mu \mathrm{g} \mathrm{m}^{-3}\right)$, and $\mathrm{Tr}$ is the filter transmission, calculated using attenuation data measured by the aethalometer (22). Kirchstetter and Novakov further adjusted for differences in BC concentrations 
measured via the aethalometer and thermal-optical analysis in their experiments. In this study, we used the manufacturer's calibration for the attenuation coefficient $\left(16.6 \mathrm{~m}^{2} \mathrm{~g}^{-1}\right)$ because time-averaged $\mathrm{BC}$ concentrations from the aethalometer were in good agreement with $\mathrm{BC}$ concentrations measured in parallel via thermal optical analysis of quartz filters (5).

Video cameras were used to record the times when vehicles entered and exited the tunnel allowing for calculation of average truck speeds through the tunnel. Camera locations used here were not suitable for recording truck license plates. Based on visual observations of the traffic, it is likely that some of the trucks drove through the tunnel and were measured more than once over the 4 sampling days. Trailer loads were observed to vary from truck to truck.

\subsection{Plume Analysis}

Emission factors for individual trucks were calculated by carbon balance from analysis of exhaust plumes present in the $1 \mathrm{~Hz} \mathrm{BC}, \mathrm{PN}$, and $\mathrm{CO}_{2}$ data. An exhaust plume from a passing HD truck is shown in Figure 1 as the sudden rise, and subsequent fall of all 3 pollutant concentrations. Truck exit times from the videotape were used as a trigger to search for corresponding $\mathrm{CO}_{2}$ peaks in the data. Only the plumes of HD trucks (defined here as trucks or tractor/trailer combinations with 3 or more axles) with vertical exhaust stacks were analyzed due to the proximity of exhaust emissions to the air sampling inlets located above the traffic. Plume analyses were not attempted when multiple trucks drove by simultaneously or in rapid succession (e.g., a slow-moving truck sometimes would 
have one or more additional trucks following immediately behind it). There was no screening of the data based on $\mathrm{BC}$ or PN emissions; only recorded truck exit times and presence of a matching $\mathrm{CO}_{2}$ peak were used to determine success in identifying individual truck exhaust plumes. For a successful exhaust plume capture, $\mathrm{CO}_{2}$ was required to increase by $>30 \mathrm{ppm}$ coincident with the time of a passing truck noted on the video camera. The 12-2 $\mathrm{PM}$ average $\mathrm{CO}_{2}$ concentration inside the tunnel near the exit was $\sim 800 \mathrm{ppm}$, so the minimum $\mathrm{CO}_{2}$ increase required for a passing truck was about $4 \%$ above baseline. Exhaust plumes were identified for 50\% (226) of the 459 HD trucks traveling through the tunnel during the present study using the above criteria. Reasons for lack of success in obtaining emission factors for some trucks include insufficient increase in $\mathrm{CO}_{2}$ above tunnel background levels (this was the most common reason), under-body instead of vertical exhaust pipe (often these trucks would have failed the $\mathrm{CO}_{2}$ criterion as well), and multiple trucks passing by at nearly the same time. It is unlikely that the plume rise criterion excluded the most fuel-efficient trucks (i.e. lowest $\mathrm{CO}_{2}$ emitters) in a systematic way since $\mathrm{CO}_{2}$ levels that we measured depend mostly on the extent of dilution that occurs prior to the exhaust plume reaching our air sampling inlet. The extent of dilution varied mostly depending on the height of the truck since our sampling point was above the traffic in a ventilation tunnel above the traffic tube, as previously discussed.

$E_{\mathrm{BC}}$, the $\mathrm{BC}$ emission factor ( $\mathrm{g} \mathrm{kg}^{-1}$ fuel burned) for individual $\mathrm{HD}$ trucks was calculated by carbon balance using eq. 2 , 


$$
E_{\mathrm{BC}}=\frac{\int_{t_{1}}^{t_{2}}\left([\mathrm{BC}]_{t}-[\mathrm{BC}]_{t_{1}}\right) d t}{\int_{t_{1}}^{t_{2}}\left(\left[\mathrm{CO}_{2}\right]_{t}-\left[\mathrm{CO}_{2}\right]_{t_{1}}\right) d t} w_{c}
$$

where $w_{\mathrm{c}}=0.87$ is the mass fraction of carbon in diesel fuel, $[\mathrm{BC}]_{\mathrm{t}}$ is the time-varying mass concentration of $\mathrm{BC}$ in units of $\mu \mathrm{g} \mathrm{m}^{-3},\left[\mathrm{CO}_{2}\right]_{\mathrm{t}}$ is the time varying concentration of $\mathrm{CO}_{2}$ in $\mathrm{mg} \mathrm{C} \mathrm{m}{ }^{-3}, t_{1}$ is the time at which the plume begins, and $t_{2}$ is the time at which the plume ends. In eq. 2, all of the carbon in the fuel is assumed to be emitted as $\mathrm{CO}_{2}$. Dilution of the exhaust plume affects the magnitude of all pollutant concentrations, but the emission factor is determined from ratios of pollutants to $\mathrm{CO}_{2}$ and thus is independent of dilution. Previous studies have used similar analysis techniques $(13,19)$.

To calculate the number of particles emitted per unit of fuel burned, $E_{P N}\left(\# \mathrm{~kg}^{-1}\right)$, a similar equation was used:

$$
E_{\mathrm{PN}}=\frac{\int_{t_{1}}^{t_{t}}\left([\mathrm{PN}]_{t}-[\mathrm{PN}]_{t_{1}}\right) d t}{\int_{t_{1}}^{t_{t}}\left(\left[\mathrm{CO}_{2}\right]_{t}-\left[\mathrm{CO}_{2}\right]_{t_{1}}\right) d t} w_{c} \cdot 10^{12}
$$

where $[\mathrm{PN}]$ is in units of $\# \mathrm{~cm}^{-3}$.

As indicated in eqs. 2 and 3, pollutant concentrations were baseline-subtracted using measured values at time $t_{1}$. This time was determined manually for each truck by finding an inflection point to the left of the peak, indicating the start of the rapid rise in pollutant 
concentration associated with a truck's exhaust plume (see Figure 1). Likewise, $t_{2}$ was determined by finding an inflection point to the right of the peak. However, if the pollutant concentration at $t_{2}$ was lower than the concentration at $t_{1}, t_{2}$ was instead chosen to be the time when the $\mathrm{CO}_{2}$ concentration decreased to match that measured at $t_{1}$. This was to avoid subtracting pollutant concentrations using values below the baseline during plume integration. Plume widths $\left(t_{2}-t_{1}\right)$ were determined from $\mathrm{CO}_{2}$ data only. The plume widths for all pollutants were kept the same for each truck. They ranged from 4-12 $\mathrm{s}$ depending on the truck, with the majority of plume widths $\sim 10 \mathrm{~s}$. Carbon monoxide and unburned hydrocarbon emissions were neglected in the denominator of eq. 2 and 3 since high time-resolution measurements of these pollutants were not available.

\section{Results and Discussion}

\subsection{Black Carbon Emissions}

A histogram of $\mathrm{BC}$ emission factors is presented in Figure 2a. The distribution appears normal when the emission factors are plotted using a logarithmic rather than linear scale. Figure 2c shows emission factors for each truck plotted on log-probability axes; lognormal distributions will plot as straight lines on these axes. Only two trucks at the low end deviate from a log-normal distribution for BC. This is likely because plume integrations for $\mathrm{BC}$ lose precision at low emission levels due to high baseline $\mathrm{BC}$ concentrations inside the tunnel. Emission factors are not shown in Figure 2c below the $6^{\text {th }}$ percentile for BC because the lowest-emitting trucks had negative calculated emission factors. 
The arithmetic mean of all BC emission factors was $1.7 \mathrm{~g} \mathrm{~kg}^{-1}$ with a standard deviation of $2.3 \mathrm{~g} \mathrm{~kg}^{-1}$. The mean value reported here is $\sim 2 \times$ higher than the fleet-average value of $0.92 \pm 0.07 \mathrm{~g} \mathrm{~kg}^{-1}$ reported in Ban-Weiss et al. (5). Note that the main goal of the present study is to evaluate emission distributions, not fleet-average emission factors. Ban-Weiss et al. calculated fleet-average emission factors by apportioning pollutants in the mixed traffic bore between LD vehicles and MD and HD trucks. Potential reasons for the different average $\mathrm{BC}$ emission factor in the present plume-based study are as follows:

(1) Only trucks with vertical exhaust pipes were included - this excludes some HD trucks and virtually all MD trucks from the plume analysis, so the fleet-average emission factor reported here reflects only a subset of the truck emissions analyzed previously;

(2) There are uncertainties in calculated emission factors, such as the apportionment of $\mathrm{CO}_{2}$ in the mixed traffic bore in the fleet-average study, and the appropriate start/stop times for plume integration coupled with need to subtract baseline pollutant concentrations from measured peak levels in the current study; (3) CO was not measured at high time resolution and therefore was not included in the denominator of eq. 2. Data reported in Ban-Weiss et al. (5) indicate the $\mathrm{CO}$ effect is small ( 4\%) on average, though it may be a more significant term in the carbon balance for high-emitting trucks.

The distribution of $\mathrm{BC}$ emissions is skewed with the highest-emitting $10 \%$ of HD trucks responsible for $42 \%$ of total $\mathrm{BC}$ emissions, as shown in Figure $2 \mathrm{~d}$. This result suggests that a repair/retrofit program aimed at the dirtiest HD diesel trucks could quickly reduce $\mathrm{BC}$ emissions. Emission measurements were made as trucks neared the end of a $1-\mathrm{km}$ uphill section of highway, with an average truck speed inside the tunnel of $64 \mathrm{~km} \mathrm{~h}^{-1}$. 
Emissions from cold or idling engines, or from trucks operating under stop-and-go or high-speed cruise conditions were not observed in this study. Trailer loads varied from truck to truck and thus some of the variance in emission factors could have resulted from differences in engine speed and load, not just differences in emission rates among engines. Some heavily loaded trucks traveled more slowly through the tunnel, and vice versa, leading to a distribution of average speeds as shown in Figure 3. Further analysis showed no correlation between truck speed and fuel-normalized BC or PN emission factors in the present study. Table 2 of Gajendran and Clark (23) provides $\mathrm{PM}$ and $\mathrm{CO}_{2}$ emissions for 5 trucks, each tested at different operating weights. These data show no large (or even directionally consistent) effect of truck test weight on fuel-normalized PM emission factors, though the underlying sample size is small. Thus we believe the variation in $\mathrm{BC}$ emission factors observed in the present study is due mainly to differences in emission rates among trucks, rather than differences in vehicle speed or engine load.

\subsection{Particle Number Emissions}

As shown in Figure $2 b$ and $2 \mathrm{c}$, particle number emission factors do not follow a lognormal distribution as closely as BC. Deviation from log-normal behavior is most pronounced at the low end of the reported emission factor range. Plume integrations lose precision at low emission levels due to high background number concentrations at the tunnel exit. Emission factors are not shown in Figure 2c below the $13^{\text {th }}$ percentile for PN due to calculated negative values for the cleanest trucks. 
The arithmetic mean of the PN emission factors was $4.7 \times 10^{15} \# \mathrm{~kg}^{-1}$ with a standard deviation of $6.6 \times 10^{15} \mathrm{H} \mathrm{kg}^{-1}$. PN emissions depend on the lower size cutoff of the particle counting instrument, and thus comparisons to other studies should be made carefully. Previous on-road chase measurements of HD truck emissions using a TSI 3025A CPC (diameter $>3 \mathrm{~nm}$ ) reported $\mathrm{PN}$ emission factors between $7.2 \times 10^{15}$ and $2.0 \times 10^{16} \mathrm{\#} \mathrm{kg}^{-1}$ for a range of cruise and acceleration conditions (10). The average PN emission factor from the Caldecott tunnel was lower, but the highest-emitting truck observed in our study had an emission factor of $\sim 4 \times 10^{16} \mathrm{H} \mathrm{kg}^{-1}$.

The distribution for PN emissions was skewed with the highest-emitting $10 \%$ of HD trucks responsible for $41 \%$ of total particle number emissions, as shown in Figure $2 \mathrm{~d}$. Similar to results for $\mathrm{BC}$ discussed in the preceding section, no correlation was found between truck speed and PN emission factor. PN emissions from diesel buses measured in Australia (20) were less skewed, with the highest-emitting $25 \%$ of buses responsible for $50 \%$ of total particle emissions. Note that only high-emitting buses were analyzed in the Australian study, so a different emission distribution is expected.

\subsection{BC vs. PN relationships}

Though $>40 \%$ of both $\mathrm{BC}$ and $\mathrm{PN}$ emissions came from the highest $10 \%$ of trucks, there was minimal overlap between high PN and high BC-emitting trucks. Figure 4 plots PN against $\mathrm{BC}$ emission factors for each individual truck. The boxes in the figure show the highest-emitting 10\% (23 trucks) separately for BC and PN. Only one truck fell simultaneously in the highest-emitting $10 \%$ for both BC and PN. The highest emitters of 
$\mathrm{BC}$ tend to have low PN emission factors, and vice versa. This can be observed by the lack of points plotted in the upper right quadrant of Figure 4. The lack of overlap in the high-emitter population is consistent with a hypothesis proposed by Kittelson et al. (9), that high $\mathrm{BC}$ emissions are likely to inhibit ultrafine particle formation. This is because precursors of ultrafine PM condense onto BC particle surfaces instead of nucleating to form new particles when $\mathrm{BC}$ is abundant in the exhaust.

\subsection{Influence of Vehicle Sample Size on Uncertainty in Fleet-Average Emissions}

Motor vehicle emission inventories (e.g. 24) often rely on results from laboratory/dynamometer test results for individual vehicles obtained under carefully controlled conditions. Laboratory results must be extrapolated to represent the entire inuse vehicle population. Using the results of the current study, we address how sample size in a study of HD truck emissions could affect the uncertainty of estimated fleetaverage emissions. We note that our emission factor distribution reflects differences in emission rates among engines, although we cannot exclude real-world effects such as engine load differences due to having a mix of loaded and unloaded trucks, as discussed previously.

Sampling with replacement from the BC emission factor distribution developed in this study, Monte Carlo simulations were performed as follows: random samples of $n$ trucks were drawn from the population of measured BC emission factors shown in Figure 2a. The distributions of calculated means for 50000 such experiments are shown in Figure 5 
for each of $n=10,30,100$, and 300 . Figure 5 also shows relative standard deviations of the means for each value of $n$.

As seen in Figure 5, the main effect of larger sample size is a narrower distribution of sample means that cluster more closely around the population mean. Presuming that trucks are truly sampled at random (e.g., there is no selection bias that leads to undersampling or exclusion of high-emitting trucks), then for $n \geq 30$ any individual sample mean is about equally likely to fall above or below the population mean of $1.7 \mathrm{~g} \mathrm{~kg}^{-1}$. For $n=10$, there is a mode in the distribution of sample means at $\sim 1.3 \mathrm{~g} \mathrm{~kg}^{-1}$, with an increased chance $(56 \%)$ of negative bias in any individual sample mean. For the case of $n=10$, the sample mean is very sensitive to the inclusion or absence of a high-emitting truck in the sample. Nevertheless, we conclude that the main effect of small sample size on the results of emissions studies is increased uncertainty when extrapolating to the entire population. Although these uncertainty analysis methods can be applied to other pollutants and vehicle categories, the results reported here are specific to the case of $\mathrm{BC}$ emissions from heavy-duty diesel trucks.

As vehicles become cleaner on average in the future, skewness of the emissions distributions will increase (11), and thus sample sizes needed to extrapolate reliably from a subset of vehicles to the entire in-use vehicle fleet are expected to become more of a challenge. 


\section{Acknowledgments}

This research was supported by the California Air Resources Board under contract no. 05-309. The statements and conclusions herein are those of the authors and do not necessarily reflect the views of the project sponsor. We thank David Fairley, Tony Strawa, Tony Hansen, Susanne Hering, John McLaughlin, Andrew Kean, and Jamie Schauer for helpful discussions and technical assistance. Also thanks to Caltrans staff at the Caldecott tunnel. LBNL authors Kirchstetter and Lunden were also supported by the Director, Office of Science, Office of Basic Energy Sciences, of the U.S. Department of Energy under Contract No. DE-AC02-05CH11231.

Supporting Information Available

Table S1 (BC and PN emission factors, average speeds, and drive-by dates and times for all 226 HD diesel trucks) can be found in the Supporting Information. This information is available free of charge via the Internet at http://pubs.acs.org.

\section{References}

(1) Lloyd, A. C.; Cackette, T. A., Diesel engines: Environmental impact and control. J. Air Waste Manage. Assoc. 2001, 51, 809-847.

(2) Kennedy, I. M., The health effects of combustion-generated aerosols. Proc. Comb. Inst. 2007, 31, 2757-2770.

(3) IPCC, Climate Change 2007: The Physical Science Basis. Contribution of Working Group 1 to the Fourth Assessment Report of the Intergovernmental Panel on Climate Change [Solomon, S., D. Qin, M. Manning, Z. Chen, M. 
Marquis, K.B. Averyt, M. Tignor and H.L. Miller (eds.)]. Cambridge University Press: Cambridge, UK, and New York, NY, USA, 2007.

(4) Gertler, A. W., Diesel vs. Gasoline emissions: Does PM from diesel or gasoline vehicles dominate in the U.S.? Atmos. Environ. 2005, 39, 2349-2355.

(5) Ban-Weiss, G. A.; McLaughlin, J. P.; Harley, R. A.; Lunden, M. M.; Kirchstetter, T. W.; Kean, A. J.; Strawa, A. W.; Stevenson, E. D.; Kendall, G. R., Long-term changes in emissions of nitrogen oxides and particulate matter from on-road gasoline and diesel vehicles. Atmos. Environ. 2008, 42, 220-232.

(6) Ramanathan, V.; Carmichael, G., Global and regional climate changes due to black carbon. Nature Geoscience 2008, 1, 221-227.

(7) Hansen, J. E.; Sato, M., Trends of measured climate forcing agents. Proc. Natl. Acad. Sci. 2001, 98, 14778-14783.

(8) Bond, T. C.; Sun, H. L., Can reducing black carbon emissions counteract global warming? Environ. Sci. Technol. 2005, 39, 5921-5926.

(9) Kittelson, D. B.; Watts, W. F.; Johnson, J. P., On-road and laboratory evaluation of combustion aerosols - part 1: Summary of diesel engine results. J. Aerosol Sci. 2006, 37, 913-930.

(10) Kittelson, D. B.; Watts, W. F.; Johnson, J. P.; Schauer, J. J.; Lawson, D. R., Onroad and laboratory evaluation of combustion aerosols - part 2: Summary of spark ignition engine results. J. Aerosol Sci. 2006, 37, 931-949.

(11) Bishop, G. A.; Stedman, D. H., A decade of on-road emissions measurements. Environ. Sci. Technol. 2008, 42, 1651-1656. 
(12) Jimenez, J. L.; Mcrae, G. J.; Nelson, D. D.; Zahniser, M. S.; Kolb, C. E., Remote sensing of $\mathrm{NO}$ and $\mathrm{NO}_{2}$ emissions from heavy-duty diesel trucks using tunable diode lasers. Environ. Sci. Technol. 2000, 34, 2380-2387.

(13) Hansen, A. D. A.; Rosen, H., Individual measurements of the emission factor of aerosol black carbon in automobile plumes. J. Air Waste Manage. Assoc. 1990, 40, 1654-1657.

(14) Mazzoleni, C.; Kuhns, H. D.; Moosmuller, H.; Keislar, R. E.; Barber, P. W.; Robinson, N. F.; Watson, J. G., On-road vehicle particulate matter and gaseous emission distributions in Las Vegas, Nevada, compared with other areas. J. Air Waste Manage. Assoc. 2004, 54, 711-726.

(15) Kurniawan, A.; Schmidt-Ott, A., Monitoring the soot emissions of passing cars. Environ. Sci. Technol. 2006, 40, 1911-1915.

(16) Cadle, S. H.; Mulawa, P. A.; Ball, J.; Donase, C.; Weibel, A.; Sagebiel, J. C.; Knapp, K. T.; Snow, R., Particulate emission rates from in use high emitting vehicles recruited in Orange County, California. Environ. Sci. Technol. 1997, 31, $3405-3412$.

(17) Sagebiel, J. C.; Zielinska, B.; Walsh, P. A.; Chow, J. C.; Cadle, S. H.; Mulawa, P. A.; Knapp, K. T.; Zweidinger, R. B., PM-10 exhaust samples collected during IM-240 dynamometer tests of in-service vehicles in Nevada. Environ. Sci. Technol. 1997, 31, 75-83.

(18) Cadle, S. H.; Mulawa, P.; Hunsanger, E. C.; Nelson, K.; Ragazzi, R. A.; Barrett, R.; Gallagher, G. L.; Lawson, D. R.; Knapp, K. T.; Snow, R., Light-duty motor 
vehicle exhaust particulate matter measurement in the Denver, Colorado, area. $J$. Air Waste Manage. Assoc. 1999, 49, 164-174.

(19) Jiang, M.; Marr, L. C.; Dunlea, E. J.; Herndon, S. C.; Jayne, J. T.; Kolb, C. E.; Knighton, W. B.; Rogers, T. M.; Zavala, M.; Molina, L. T.; Molina, M. J., Vehicle fleet emissions of black carbon, polycyclic aromatic hydrocarbons, and other pollutants measured by a mobile laboratory in Mexico City. Atmos. Chem. Phys. 2005, 5, 3377-3387.

(20) Jayaratne, E. R.; Morawska, L.; Ristovski, Z. D.; He, C., Rapid identification of high particle number emitting on-road vehicles and its application to a large fleet of diesel buses. Environ. Sci. Technol. 2007, 41, 5022-5027.

(21) Wood, E.; Herndon, S.; Trimborn, A.; Nelson, D.; Jayne, J.; Knighton, B., Measurements of diesel exhaust in Mexico and the southwest U.S. Eos Trans. AGU 2005, 86, Fall Meet. Suppl., Abstract A51E-0122 (Poster).

(22) Kirchstetter, T. W.; Novakov, T., Controlled generation of black carbon particles from a diffusion flame and applications in evaluating black carbon measurement methods. Atmos. Environ. 2007, 41, 1874-1888.

(23) Gajendran, P.; Clark, N. N., Effect of truck operating weight on heavy-duty diesel emissions. Environ. Sci. Technol. 2003, 37, 4309-4317.

(24) Bond, T. C.; Streets, D. G.; Yarber, K. F.; Nelson, S. M.; Woo, J. H.; Klimont, Z., A technology-based global inventory of black and organic carbon emissions from combustion. J. Geophys. Res. 2004, 109, doi:10.1029/2003JD003697. 
Table of Contents brief:

On-road measurement of black carbon and particle number emissions from 226 heavyduty diesel trucks revealed the importance of sufficiently high vehicle sample size in emissions studies. 

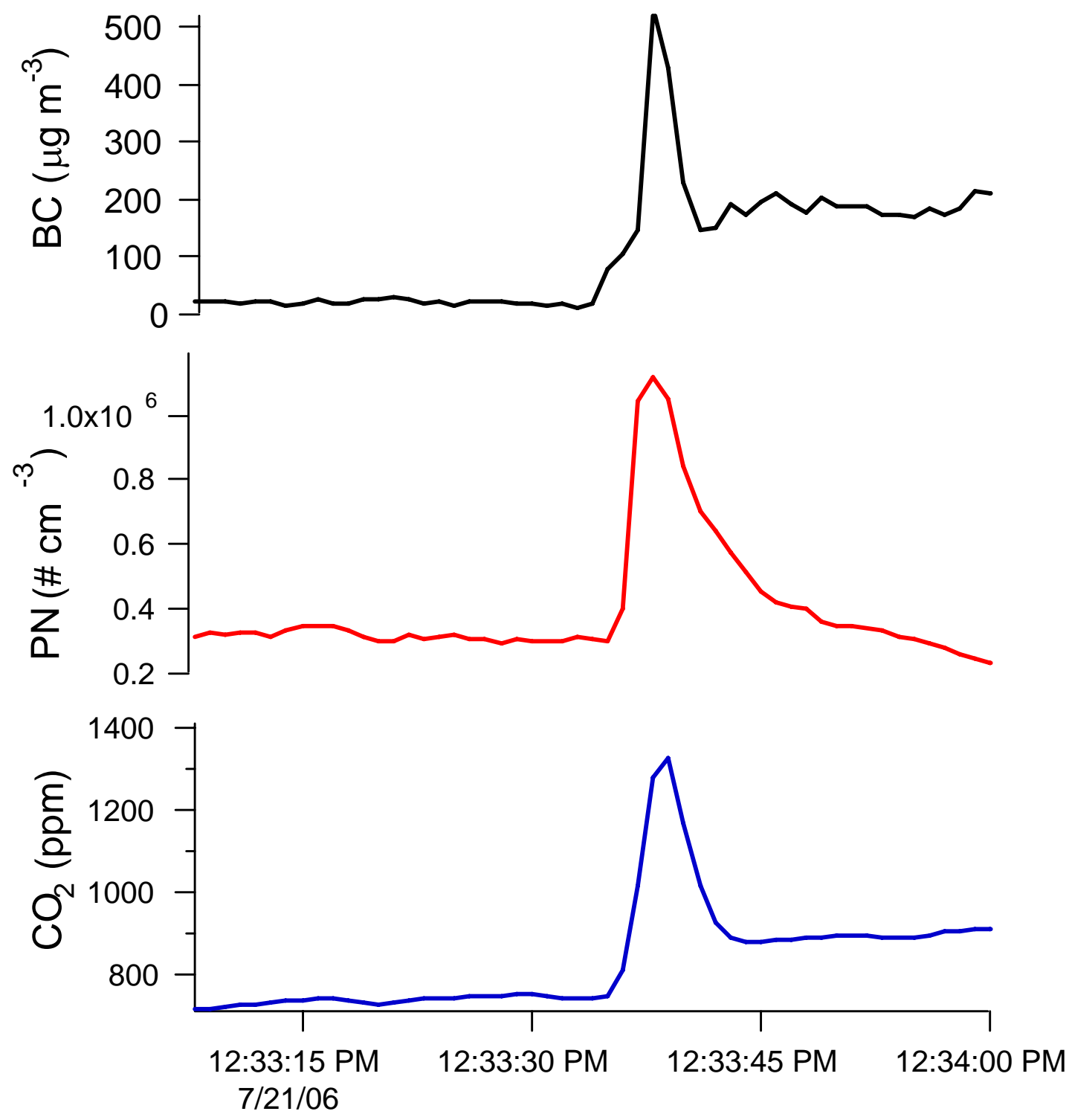

Figure 1. Measured black carbon (BC), particle number $(\mathrm{PN})$, and $\mathrm{CO}_{2}$ concentrations in the exhaust plume of a passing HD truck. 

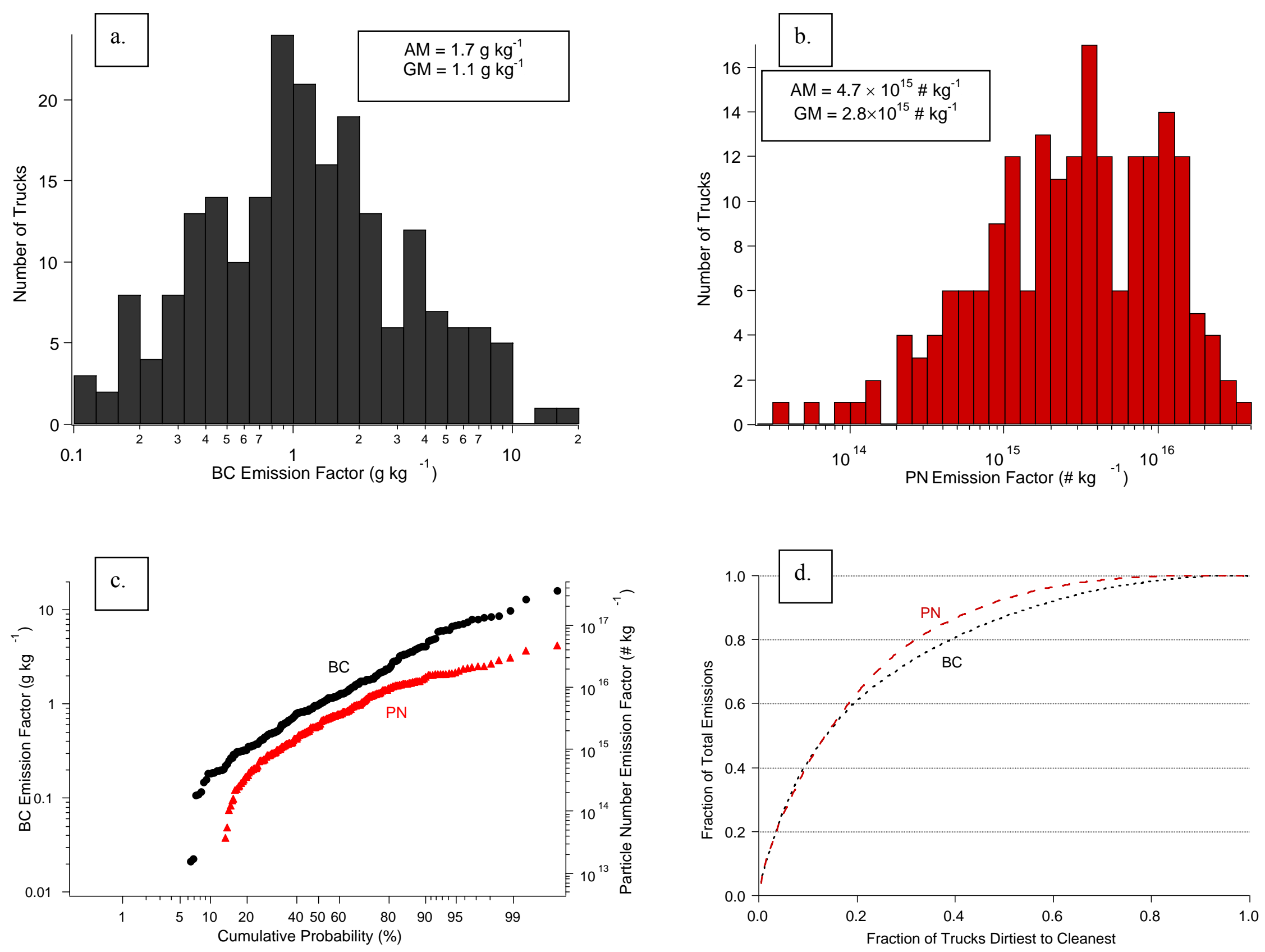
Figure 2. Histogram of BC (a) and PN (b) emission factors from trucks driving through the Caldecott tunnel during summer 2006. Arithmetic mean (AM) and geometric mean (GM) emission factors are presented in the text boxes. Also shown is a probability plot of the emission factors (c) for BC and PN from the 226 individual HD trucks. The horizontal axis shows the probability that a truck has an emission factor less than the indicated value. Log-normal distributions plot as straight lines on these axes. The cumulative distributions (d) indicate that the highest-emitting $10 \%$ of trucks are responsible for $\sim 40 \%$ of total BC and PN. If all vehicles had identical emission rates, this would plot as a 1:1 diagonal line in (d). 


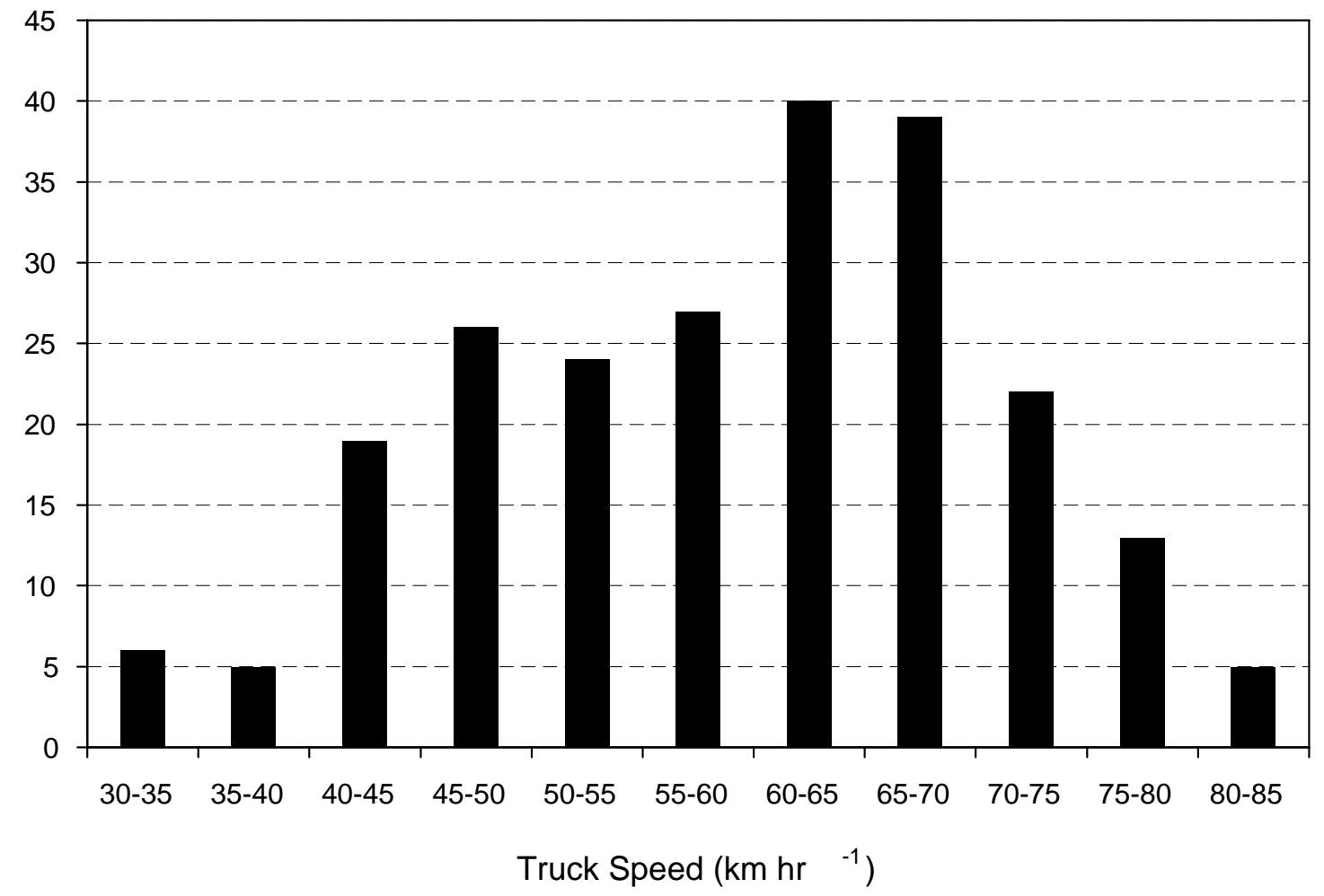

Figure 3. Truck speed distribution for the $226 \mathrm{HD}$ trucks analyzed in this study, based on average values per truck through the tunnel. 


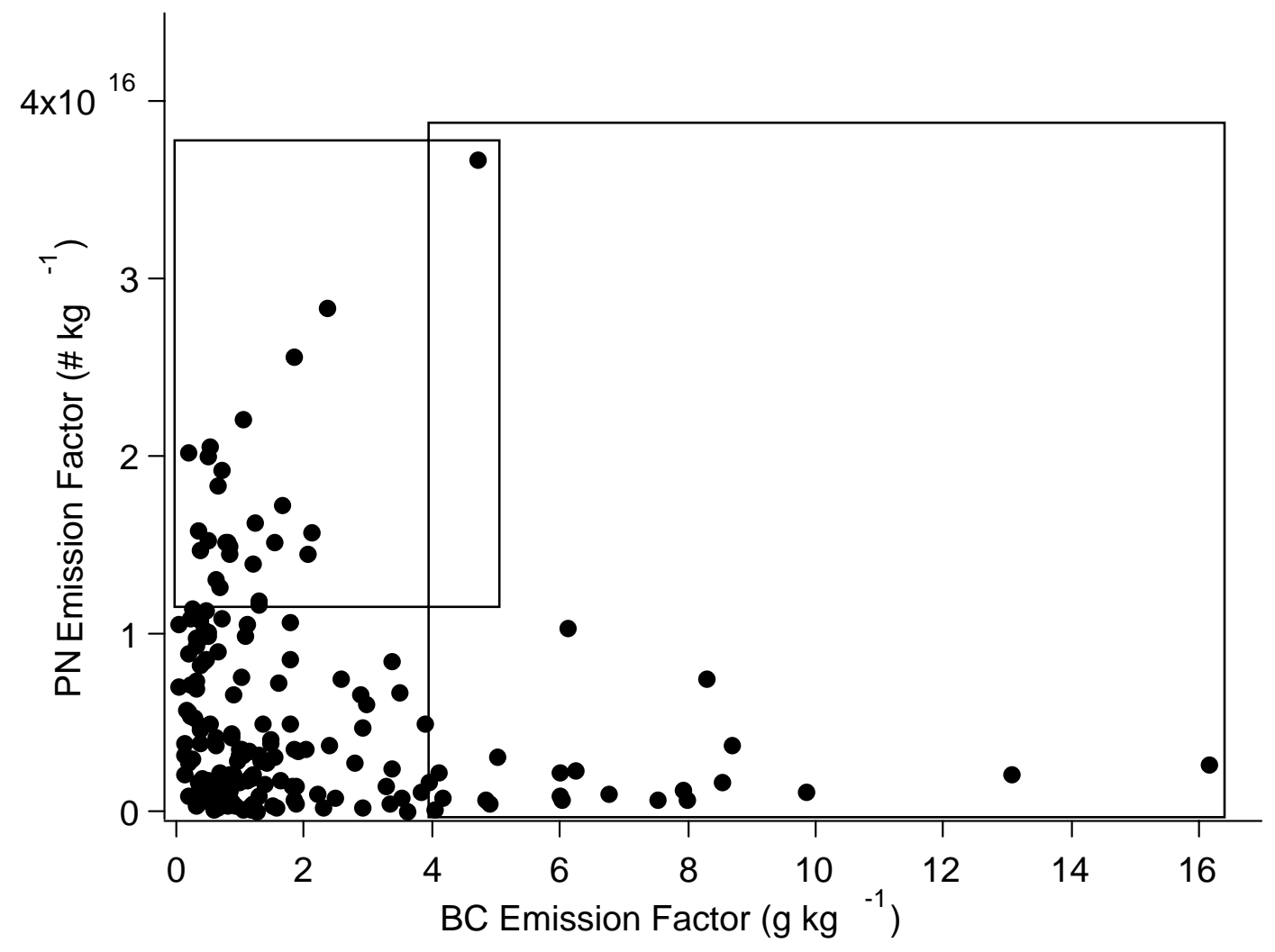

Figure 4. Emission factors for particle number (PN) plotted against matched black carbon (BC) emission factors for individual HD trucks. Boxes highlight the highest $10 \%$ of emitters for each pollutant; note minimal overlap of high-emitters. 


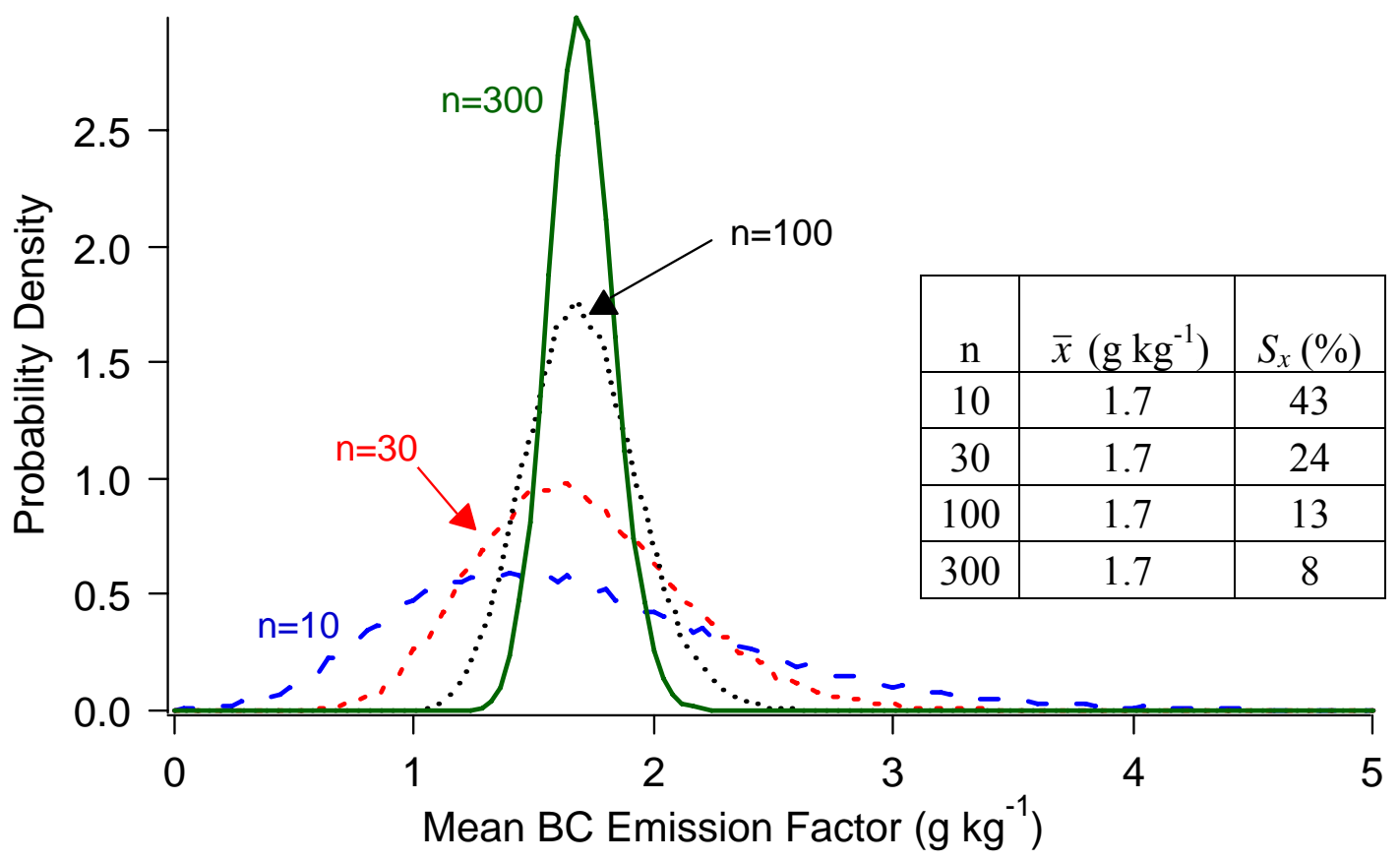

Figure 5. Probability density function of simulated sample means of BC emission factors for $\mathrm{n}=10,30,100$, and $300 \mathrm{HD}$ trucks. Tabulated values are number of vehicles sampled (n) in each iteration, grand mean $(\bar{x})$ of sample means, and relative standard deviation $\left(S_{x}\right)$ of the sample means over 50,000 simulated samples (with replacement) from the distribution of $\mathrm{BC}$ emission factors shown in Figure 2. 